\title{
CONF-970469--
}

\section{SIMULATION TOOLS FOR ROBOTIC AND TELEOPERATED HAZARDOUS WASTE REMOVAL *}

\author{
L. J. Love \\ Oak Ridge Institute for Science and Education \\ P.O. Box 2008 \\ Oak Ridge, Tennessee 37831-6426 \\ (423) $576-4630$ \\ R. L. Kress and K. C. Bills \\ Robotics and Process Systems Division \\ Oak Ridge National Laboratory \\ P. O. Box 2008 \\ Oak Ridge, Tennessee 37831-6426 \\ (423) $574-2468$ \\ (423) $576-5884$ \\ RECEIVED \\ FFA 251998 \\ OSTI
}

\section{3}

To be presented at the ICRA'97

on IEEE Robotics and Automation Society in Albuquerque, New Mexico

April 20 - 25, 1997

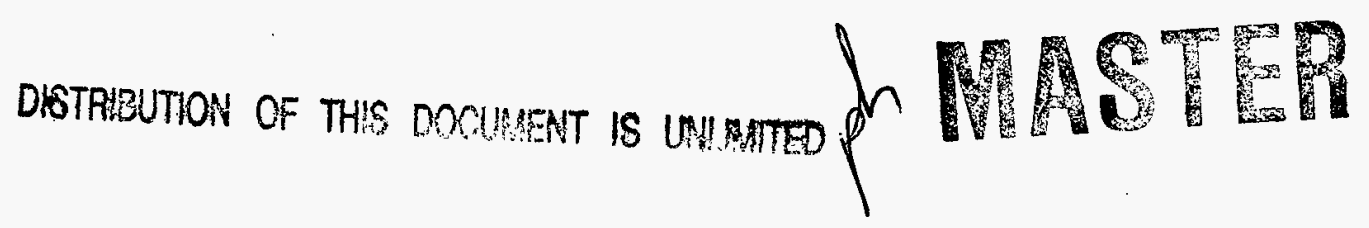

*Oak Ridge National Laboratory, managed by Lockheed Martin Energy Research Corp. for the U.S. Department of Energy under contract number DE-AC05-960R22464. 


\section{DISCLAIMER}

This report was prepared as an account of work sponsored by an agency of the United States Government. Neither the United States Government nor any agency thereof, nor any of their employees, makes any warranty, express or implied, or assumes any legal liability or responsibility for the accuracy, completeness, or usefulness of any information, apparatus, product, or process disclosed, or represents that its use would not infringe privately owned rights. Reference herein to any specific commercial product, process, or service by trade name, trademark, manufacturer, or otherwise does not necessarily constitute or imply its endorsement, recommendation, or favoring by the United States Government or any agency thereof. The views and opinions of authors expressed herein do not necessarily state or reflect those of the United States Government or any agency thereof. 


\section{SIMULATION TOOLS FOR ROBOTIC AND TELEOPERATED HAZARDOUS WASTE REMOVAL*}

L. Love

Oak Ridge National Laboratory

P.O. Box 2008

Oak Ridge, Tennessee 37831-6426

\author{
R. Kress \\ Oak Ridge National Laboratory \\ P.O. Box 2008 \\ Oak Ridge, Tennessee 37831-6426
}

\author{
K. Bills \\ Oak Ridge National Laboratory \\ P.O. Box 2008 \\ Oak Ridge, Tennessee 37831-6426
}

\section{ABSTRACT}

The primary mission of Oak Ridge National Laboratory (ORNL) during World War II was the processing of pure plutonium metal in support of the Manhattan Project. Between 1943 and 1951, the Gunite and Associated Tanks (GAAT) at ORNL were built to collect, neutralize, and store the radioactive by-products. Currently, twelve gunite tanks and four stainless steel tanks are located on the ORNL complex. These tanks hold approximately 75,000 gal of radioactive sludge and solids and over 350,000 gal of liquid. Characterization studies of these tanks in 1994 indicated that the structural integrity of some of the tanks is questionable. Subsequently, there is presently an aggressive program directed towards the remediation and relocation of waste stored in the ORNL tanks. A number of factors complicate the remediation process. The material stored in these tanks ranges from liquid to sludge and solid and is composed of organic materials, heavy metals, and radionuclides. The tanks, which range from 12 to $50 \mathrm{ft}$ in diameter, are located below ground and in the middle of the ORNL complex. The only access to these tanks is through one of three access ports that are either 12 or 24 in. in diameter. ${ }^{1}$ These characteristics provide a daunting challenge: How can material be safely removed from such a confined structure? This paper describes the existing strategy and hardware presently used in the remediation process. This is followed by a description of an integrated hardware system model. This investigation has isolated a few key areas where further work is needed.

\section{INTRODUCTION}

As part of a Comprehensive Environmental Response, Compensation, and Liability Act Treatability Study funded by the Department of Energy (DOE), ORNL is preparing to demonstrate and evaluate two approaches for the remote retrieval of waste in underground storage tanks. This work is being performed

*Oak Ridge National Laboratory, managed by Lockheed Martin Energy Research Corp. for the U.S. Department of Energy under contract number DE-AC05-96OR22464. to identify the most cost-effective and efficient method of waste removal before full-scale remediation efforts begin in 1998. One of the strategies focuses on the use of multiple long-reach manipulators for waste retrieval. With this approach, two robots operate cooperatively to guide a Confined Sluicing End-Effector (CSEE) through the waste. The first robot, the Hose Management Arm (HMA), carries the CSEE, which breaks up and sucks out a host of materials from the tank. The second robot, the Modified Light Duty Utility Arm (MLDUA), grasps the CSEE and moves it over the waste surface. This process can be executed either autonomously or via teleoperation command. ${ }^{2}$

\section{A. Modified Light Duty Utility Arm}

The large volume and small access ports in the tanks require a robot that is both long and slender. In addition, the manipulator will interact with the environment and carry a host of tools. Subsequently, the robot will need a relatively high payload capacity. Spar Aerospace is providing ORNL's Robotics and Process Systems Division (RPSD) a robot that achieves each of these requirements. The MLDUA is an 8-degree-of-freedom (D.O.F.) manipulator that has a $15.0 \mathrm{ft}$ reach and $200-1 b$ payload capacity. Furthermore, the robot has a maximum cross-section diameter of 9 in., ensuring easy access into any of the ORNL tanks. ${ }^{3}$

\section{B. Hose Management Arm}

The second robot deployed during the remediation process is the HMA. This arm has 4-D.O.F. and is used to carry a hose and the CSEE. The CSEE has a vacuum pump and rotating head with high-pressure water jets. The combination of water jets and vacuum enables the CSEE to break up a wide range of solids and transport the waste from the tank, through an exhaust hose and the HMA, into a secondary storage facility. Figure 1 shows the hardware working in a simulated tank.

\section{Cold Test Facility}


For proof of concept, ORNL has constructed a Cold Test Facility (CTF) in which all of the hardware will be deployed in an attempt to simulate the conditions expected during a remediation process. The CTF is located on the grounds of the RPSD. The facility includes a control building, an underground test pit, and a surveillance platform. All of the operator interface and communication hardware is located in the control building. This facility permits full control over the visual and tactile cues an operator will experience during an operation. All of the hardware related to the robots is located on a platform above the pit. The platform is built to the same specifications as the platforms to be used in the field. Furthermore, the risers that permit access from the platform into the pit are built to the same specifications as the risers entering the underground storage tanks. Finally, the pit is located below ground directly underneath the hardware platform. A wide variety of hardware and simulated waste can be easily deployed in the pit for simulated waste removal. In addition, an observation platform provides an avenue for safe and direct visual inspection of the pit during operation. The CTF will serve a number of purposes. Primarily, it will act as a training tool for hardware deployment and operator training. In addition, any hardware and software modifications may be tested in this facility prior to deployment in a radioactive environment.

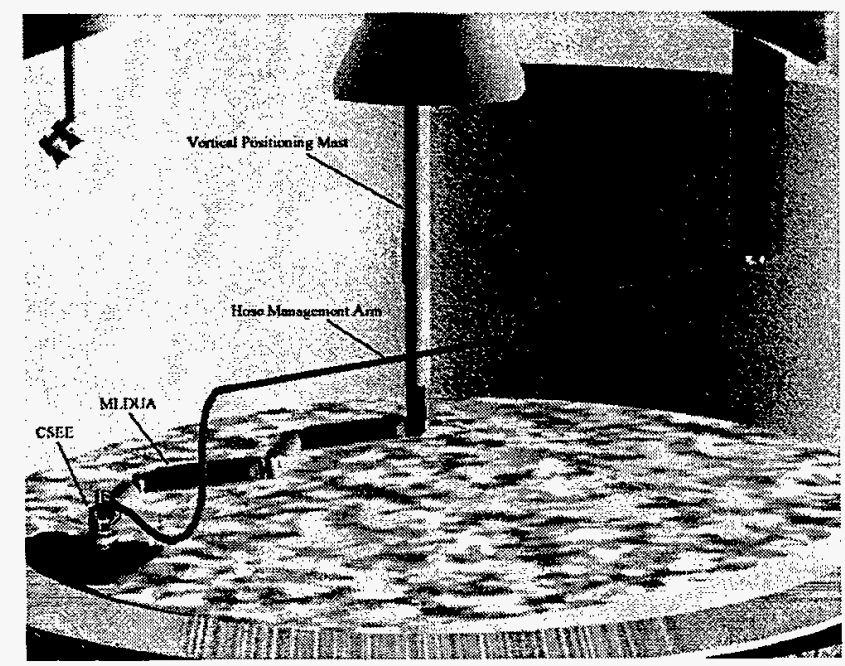

Figure 1: Gunite Tank and Associated Hardware

\section{SIMULATION TOOLS}

ORNL has developed a number of simulation tools to aide in investigating any potential problems that may arise during the remediation process. An integrated system model of the hardware, illustrated in Fig. 1, is operational under a TeleGrip ${ }^{\mathrm{a}}$ simulation program. The system model includes a detailed model of the MLDUA (complete with Spar's inverse kinematics algorithm) and a dynamic model of the HMA and flexible exhaust hose connecting the two arms. The goal of the system model is threefold:

- The model shall provide a tool for operator training. The system can simulate teleoperation input commands through the same interface available on the hardware. Lighting and camera views may be adjusted to identify optimal viewing ports for operation.

- The model shall provide a benchmark for identifying potential mining strategies. A working model of the CSEE and waste provides a visual cue simulating waste removal. As the operator moves the CSEE through the waste, the texture of the waste surface varies with the amount of material remaining. It is also possible to record the net amount of material removed during a mining process.

- The model shall provide an interface capable of investigating alternative control strategies for the HMA. Alternative control strategies are imbedded in the simulation.

\section{A. Stand-Alone Model of the MLDUA}

In the fall of 1995, Spar Aerospace provided a standalone TeleGrip model of the MLDUA to the Idaho National Engineering Laboratory. This model has since been made available to ORNL. This TeleGrip model features many novel characteristics, including accurate modeling of the MLDUA's kinematics, teleoperation or robotic input commands, and realistic response to these commands. Furthermore, the algorithm for the inverse kinematics used to resolve the joint angles from Cartesian commands is the same algorithm that will be used on the real hardware. The master input device, a pair of 3-D.O.F. joysticks, can be used to provide desired translational and rotational velocity input commands to the model by an operator.

\section{Hose}

B. Dynamic Modeling of the HMA and

To better understand the coordinated motion of MLDUA and HMA, a comprehensive modeling effort was focused on integrating a dynamic model of the HMA

${ }^{a}$ TeleGrip is a versatile graphical and dynamic robotic simulation package produced by Deneb, Inc. 
and hose with the stand-alone MLDUA model. During operation, the total system is quite complex. The MLDUA grasps the CSEE, which is coupled to the HMA by a long, flexible hose. Thus, during operation, the entire system consists of a closed kinematic chain with a flexible hose acting as one of the links in the chain. One of the challenges during the modeling process was the solution of the kinematics of the hose and HMA. The strategy for dynamic simulation consists of treating the tip position of the MLDUA as an input into a dynamic model of the hose and HMA. Movement of the MLDUA, and subsequently one end of the hose, produces a deformation of the hose from its equilibrium. A joint torque on the hose model is computed by the product of the hose stiffness, $K_{h}$, and joint deformation. This deformation provides a resultant reaction force at the tip of the HMA and MLDUA. This reaction force drives a dynamic model of the HMA that will subsequently provide an updated tip position of the HMA (and subsequently, a new hose position for the next iteration of the algorithm).

1. Energy Model of the HMA. The HMA is modeled as a 2-D.O.F. planar manipulator operating in the horizontal plane. The dynamic model includes inertial effects, $\mathrm{D}\left(\mathrm{q}_{\mathrm{hma}}\right)$, and nonlinear coupling and friction terms, $C\left(\mathrm{q}_{\mathrm{hma}}, \dot{\mathrm{q}}_{\mathrm{hma}}\right)$. The model also includes external inputs to the robot from tip and joint forces. The tip force, $F_{\text {hose }}$, currently used in the integrated system model is provided by the deformation of the hose. The computation of this force is described shortly. Joint forces may be generated by the motors under some form of joint level control, $\tau_{\text {control }}$. In the current planar model of the hose, an additional joint torque is produced by the deformation of the hose yaw joint, $q_{e}$.

$$
\begin{aligned}
& D\left(q_{\text {hma }}\right) \ddot{q}_{\text {hrua }}+C\left(q_{\text {hma }}, \dot{q}_{\text {hma }}\right) \dot{q}_{\text {hma }}=J_{\text {hma }}^{\prime}\left(q_{\text {hom }}\right) F_{\text {hoce }} \\
& +\tau_{\text {conarol }}+\mathrm{K}_{\mathrm{h}} \mathrm{q}_{\mathrm{e}}
\end{aligned}
$$

Subsequently, the dynamic model consists of computing the joint motion, $\mathrm{q}_{\mathrm{hma}}$, due to external forces applied at the tip and joints of the robot. The joint motion can then be transformed to motion at the tip of the HMA. This provides the location of the second end of the hose, where the first end is located at the tip of the MLDUA.

2. Hose Boundary Conditions. As stated earlier, the hose and HMA model have a few novel boundary conditions. First, one end of the hose must terminate at the CSEE, held by the MLDUA. The second end of the hose terminates at the end of the HMA. However, when the HMA is not under control (passive), only the vertical position is fixed, and the robot is free to move in the horizontal plane. The combined motion of the MLDUA and HMA is resolved by combining the dynamics of the HMA with the boundary condition of the hose. The HMA has an initial configuration that minimizes the horizontal distance between the tips of the two robots. In addition, the static configuration of the hose, $\mathrm{q}_{\mathrm{s}}$, is computed once. This is the hose configuration that would result if the hose was hanging freely from the tip of the HMA. An iterative process consists of first calculating the current tip position of the HMA and MLDUA. Next, the horizontal and vertical distance, as well as angle $q_{e}$, between the two robot tips is calculated. A resulting joint torque at each joint of the hose can be computed by calculating the deformation of the joint from its equilibrium position.

$$
\tau_{\mathrm{i}}=\mathrm{K}_{\mathrm{h}}\left(\mathrm{q}_{\mathrm{st}}-\mathrm{q}_{\mathrm{i}}\right)
$$

This vector of joint torques on the hose can then be transformed to a reaction force, $F_{\text {hose }}$, at the tip of the HMA by computing the Jacobian between the hose generalized coordinates, $\mathrm{q}_{\mathrm{i}}$, and the Cartesian space of the HMA. This hose force is one of the inputs to the HMA dynamic model. Given this external force, the HMA will move accordingly and provide a new tip position for the next iteration of the algorithm. The final piece of the puzzle is the computation of the hose coordinates, $\mathrm{q}_{\mathrm{i}}$.

3. Energy Model of Hose. A lumped spring-mass model is used to model the dynamics of the flexible hose connecting the HMA to the tip of the MLDUA. In the model, six links are used to represent the $7.5 \mathrm{ft}$-long flexible hose. Each joint has both a yaw and pitch joint. However, for the present model, only the first joint uses both yaw and pitch at the junction of the hose and HMA. The remaining joints use only the pitch joint. Under this model, the hose deforms in the vertical plane. For three degrees of Cartesian deformation, an additional yaw joint is added connecting the hose to the tip of the HMA. Figure 2 illustrates a conceptual model of the hose.

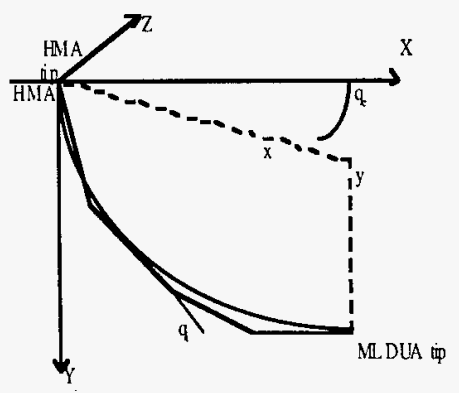

Figure 2: Hose Kinematics 
To solve for the configuration of the hose, a potential energy model was initially used. The energy in this model includes gravitational energy associated with the mass and compliance energy associated with the springs at each joint. The values used for the mass and compliance were experimentally determined on the hose used for the remediation task. Equation (3) represents the potential energy equation.

$$
\mathrm{V}=\frac{1}{2} \sum_{\mathrm{i}=1}^{\mathrm{N}} \mathrm{K}_{\mathrm{h}} \mathrm{q}_{\mathrm{i}}^{2}-\sum_{\mathrm{i}=1}^{\mathrm{N}} \mathrm{m}_{\mathrm{i}} \mathrm{g} \mathrm{y}_{\mathrm{i}}
$$

The hose stiffness is $\mathrm{K}_{\mathrm{h}}$, and the distributed mass of the hose is $\mathrm{m}$, with $\mathrm{g}$ representing gravity. The vertical distance between the tip of the HMA and MLDUA, $y$, is defined in Eq. (4).

$$
y_{i}=\sum_{j=1}^{i} \frac{L}{N} \sin \left(\sum_{k=1}^{j} q_{k}\right)
$$

The solution of the inverse kinematics of the hose model must both minimize the energy while satisfying this length constraint.

4. Linearized Energy Model of Hose. The strategy adopted for solving for the configuration of the hose consists of finding the hose configuration that minimized the potential energy, Eq. (3), while satisfying the boundary conditions described in Sect. 2.A.2. Define the vertical and horizontal distance between the tips of the two arms as $\mathrm{x}$ and $\mathrm{y}$ respectively. These distances are directly computed from the measured tip position of the HMA and MLDUA. The goal is to find the hose joint coordinates that minimize the potential energy of the arm while at the same time satisfying the required vertical and horizontal distance constraints.

$$
x=\sum_{j=1}^{N} \frac{L}{N} \cos \left(\sum_{k=1}^{j} q_{k}\right) \text { and } y=\sum_{j=1}^{N} \frac{L}{N} \sin \left(\sum_{k=1}^{j} q_{k}\right)^{5)}
$$

Under these conditions, we are left with the following functional to minimize with respect to the hose joint coordinates.

$$
\begin{aligned}
& F=\frac{1}{2} \sum_{i=1}^{N} K_{h} q_{i}^{2}-\sum_{i=1}^{N} m_{i} g \sum_{j=1}^{i} \frac{L}{N} \sin \left(\sum_{k=1}^{j} q_{k}\right)+ \\
& \lambda_{i}\left(x-\sum_{j=1}^{N} \frac{L}{N} \cos \left(\sum_{j=1}^{i} q_{j}\right)\right)+\lambda_{1}\left(y-\sum_{j=1}^{N} \frac{L}{N} \sin \left(\sum_{j=1}^{i} q_{j}\right)\right)
\end{aligned}
$$

After minimizing Eq. (6) with respect to the $\mathrm{N}$ generalized hose coordinates and the two Lagrange multipliers, we are left with the following $\mathrm{N}+2$ nonlinear equations.

$$
\begin{gathered}
\mathrm{K}_{\mathrm{h}} \mathrm{q}_{\mathrm{r}}+\lambda_{\mathrm{l}} \sum_{j=\mathrm{r}}^{N} \frac{\mathrm{L}}{N} \sin \left(\sum_{j=1}^{i} \mathrm{q}_{j}\right)-\lambda_{1} \sum_{j=1}^{N} \frac{L}{N} \cos \left(\sum_{j=1}^{i} q_{j}\right)= \\
\sum_{i=r}^{N} \mathrm{~m}_{i} g \sum_{j=1}^{i} \frac{L}{N} \sin \left(\sum_{k=1}^{j} q_{k}\right) \\
x=\sum_{j=1}^{N} \frac{L}{N} \cos \left(\sum_{k=1}^{j} q_{k}\right) \\
y=\sum_{j=1}^{N} \frac{L}{N} \sin \left(\sum_{k=1}^{j} q_{k}\right)
\end{gathered}
$$

First, substitute Eq. (10) into Eqs. (8) and (9) to provide a localized linear expression of the trigonometric functions. Then Eqs. (7) to (9) can be combined and rearranged to provide the relationship in Eq. (11). The index $\mathrm{k}$ represents the iteration of the algorithm.

$$
\begin{aligned}
& \sin \left(\mathrm{q}_{\mathrm{i}}[\mathrm{k}]\right) \equiv \sin \left(\mathrm{q}_{\mathrm{i}}[\mathrm{k}-1]\right) \\
& \quad-\mathrm{q}_{\mathrm{i}}[\mathrm{k}-1] \cos \left(\mathrm{q}_{\mathrm{i}}[\mathrm{k}-1]\right)+\mathrm{q}_{\mathrm{i}}[\mathrm{k}] \cos \left(\mathrm{q}_{\mathrm{i}}[\mathrm{k}-1]\right) \\
& \cos \left(\mathrm{q}_{\mathrm{i}}[\mathrm{k}]\right) \cong \cos \left(\mathrm{q}_{\mathrm{i}}[\mathrm{k}-1]\right) \\
& \quad+\mathrm{q}_{\mathrm{i}}[\mathrm{k}-1] \sin \left(\mathrm{q}_{\mathrm{i}}[\mathrm{k}-1]\right)-\mathrm{q}_{\mathrm{i}}[\mathrm{k}] \sin \left(\mathrm{q}_{\mathrm{i}}[\mathrm{k}-1]\right)
\end{aligned}
$$




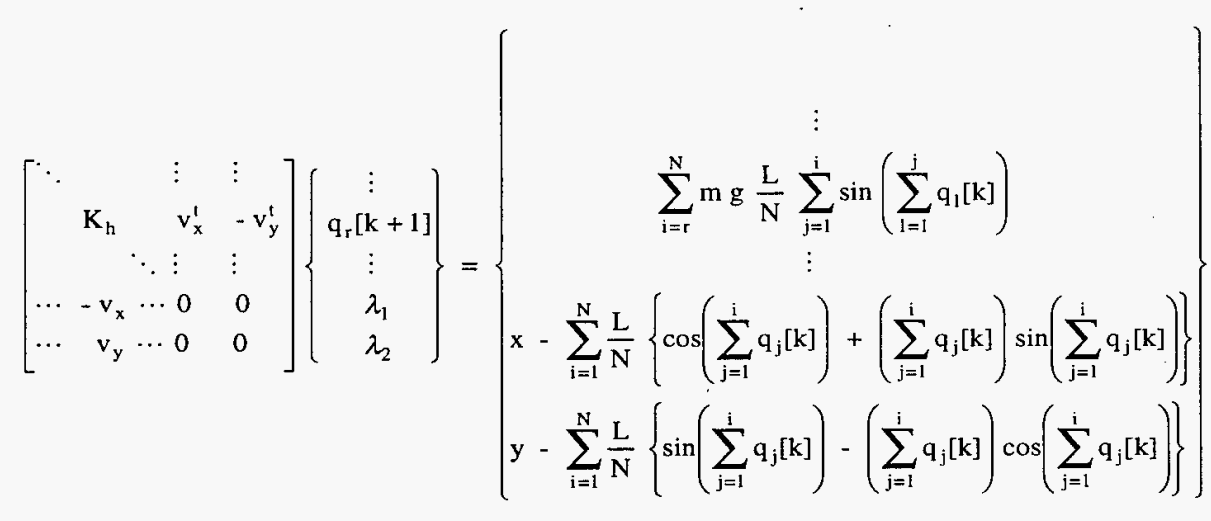

with

$$
\begin{aligned}
& v_{x}(r)=\frac{L}{N} \sum_{j=r}^{N} \sin \left(\sum_{l=1}^{j} q_{l}[k]\right) \\
& v_{y}(r)=\frac{L}{N} \sum_{j=r}^{N} \cos \left(\sum_{l=1}^{j} q_{l}[k]\right)
\end{aligned}
$$

The above equation can then be put into a simple linear format.

$$
[\mathrm{A}(\overline{\mathrm{q}}[\mathrm{k}])]\left\{\begin{array}{c}
\overline{\mathrm{q}}[\mathrm{k}+1] \\
\lambda_{1} \\
\lambda_{2}
\end{array}\right\}=\{\mathrm{B}(\overline{\mathrm{q}}[\mathrm{k}])\}
$$

The solution to the hose joint angles now falls to the solution of $\mathrm{N}+2$ linear equations. Furthermore, the solution can take the form of a recursive algorithm that, as the hose tip position varies, the algorithm will solve for the hose configuration accordingly. For the work described in this paper, the Newton-Gauss Elimination proved to be robust and computationally efficient.

5. Hose Interaction Force. The next issue related to the hose model is the resultant force applied to the HMA from the hose. The strategy adopted in this modeling effort is to compute the effective torque at each joint and define a Jacobian from the hose joint space to the coordinates on the tip of the HMA. The joint torque is the product of the joint stiffness and the deviation of the joint position from its equilibrium configuration. First, an estimation of the static configuration of the hose is necessary. An iterative solution to the static generalized coordinates is sought which satisfies Eq. (14).

$$
\left[\begin{array}{ccc}
\ddots & \\
& \mathrm{K}_{\mathrm{h}} \\
& \ddots
\end{array}\right]\left\{\begin{array}{c}
\vdots \\
\mathrm{q}_{\mathrm{st}}[\mathrm{k}+1] \\
\vdots
\end{array}\right\}=\left\{\begin{array}{c}
\vdots \\
\sum_{\mathrm{i}=4}^{\mathrm{N}} \mathrm{mg} \frac{\mathrm{L}}{\mathrm{N}} \sum_{\mathrm{j}=1}^{\mathrm{i}} \sin \left(\sum_{\mathrm{l}=1}^{\mathrm{j}} \mathrm{q}_{\mathrm{st}}[\mathrm{k}]\right. \\
\vdots
\end{array}\right\}
$$

The above equation will converge to the static hose configuration, $\mathrm{q}_{\mathrm{st}}$. This can be computed off-line. This provides all the information necessary to compute the hose joint torque vector for a specific hose configuration.

$$
\bar{\tau}_{\text {hosc }}=\left[\mathrm{K}_{\mathrm{h}}\right]\left\{\overline{\mathrm{q}}-\overline{\mathrm{q}}_{\mathrm{st}}\right\}
$$

The Jacobian between the hose generalized coordinates and the tip of the HMA provides the transformation necessary to generate the tip force on the end of the HMA.

$$
\overline{\mathrm{F}}_{\text {hose }}=\mathrm{J}_{\text {hose }}^{\mathrm{t}} \bar{\tau}_{\text {hose }}
$$

\section{SIMULATION STUDIES}

One of the preliminary goals of the integrated system model was to establish any limitations that may exist in the combined hardware when deployed in the tank. From this study, we should establish further direction of research issues that must be addressed prior to hardware deployment.

\section{A. Inverse Kinematics}

One of the fundamental questions regarding the MLDUA is the strategy for resolving the redundancy in the kinematics. The existing Spar redundancy resolution calls for the arm to take a Scara configuration. Figure 3 illustrates an example configuration when the arm moves near the waste surface. It is evident from this picture that a large portion of the robot's arm will always be close to the surface of the waste. This may not be desirable. There is a potential for collision with in-tank hardware, solid waste, and other debris that may be located near the surface of the waste. Alternative inverse kinematics solutions are sought that could adopt a slightly different criteria. One example could be identifying the joint configuration that maximizes the distance between the 
waste surface and the links of the robot. Another potential strategy with the inverse kinematics is to increase the redundant degree-of-freedom by reducing the active Cartesian degree-of-freedom. Figure 4 illustrates how commanding a fixed orientation on the robot during a straight-line motion can force the arm into a singular configuration. During such operations, wrist yaw can be neglected, thereby reducing the active Cartesian degree-offreedom to five. This simple enhancement could enable the robot to easily maneuver past this singularity.

\section{B. Cooperative Control of Dual Arms} with Passive Links

Another potential problem with the integrated hardware is the dynamics of the combined MLDUA/HMA. Figure 5 illustrates a potential breach of the tank due to the HMA colliding with the tanks walls. Some advanced form of cooperative control of the HMA and MLDUA may provide extended workspaces as well as ensure safe operation.

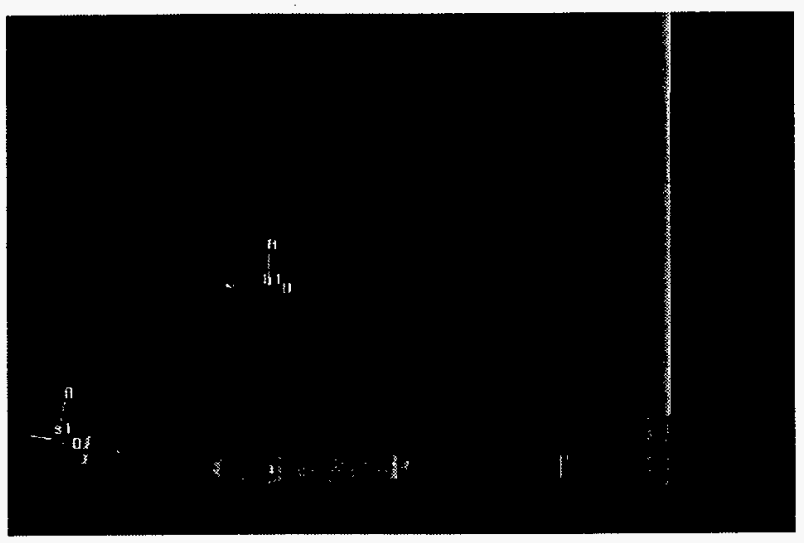

Figure 3: Scara configuration near waste

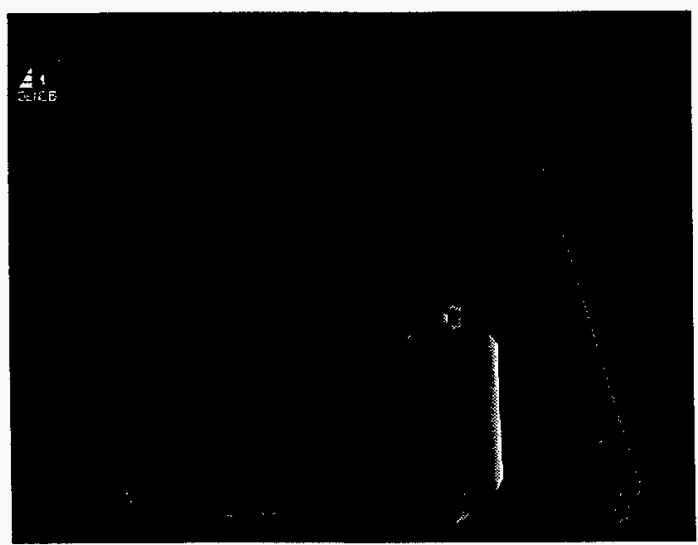

Figure 4: Joint limits with 6 Cartesian Degree-of-Freedom

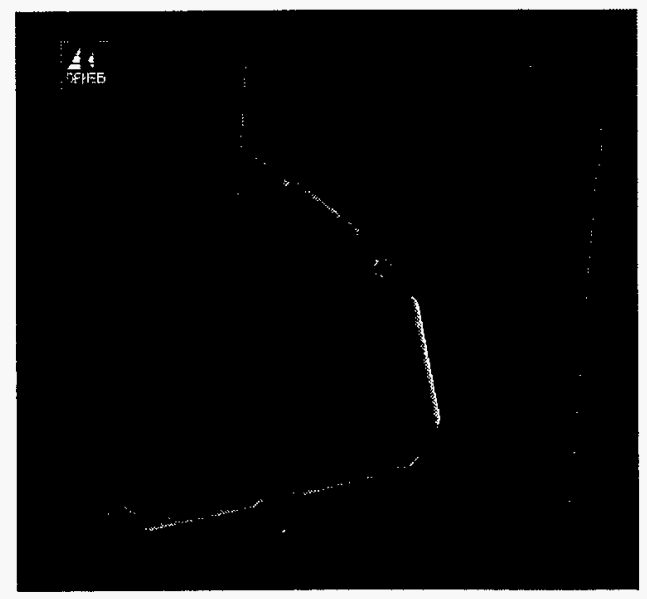

Figure 5: Collision with tank

\section{v. CONCLUSIONS}

A comprehensive integrated system model of the gunite tanks and waste remediation hardware has been successfully modeled under the TeleGrip simulation platform. The model permits simulation of remediation tasks under either robotic or teleoperated commands. Presently, the system is being used to develop mining strategies and to understand the physical constraints of the hardware. The model is flexible in that it will permit future studies of alternative kinematic resolution and cooperative control strategies of the dual-arm system.

\section{ACKNOWLEDGMENTS}

The authors would like to thank Spar Aerospace for the TeleGrip model of the MLDUA and the Robotics Technology Development Program at Sandia National Laboratories for their financial support.

\section{REFERENCES}

1. D. Van Hoesen, F. Bzorgi, A. Kelsey, C. Wiles, and K. Beeson, "Underground Radioactive Waste Tank Remote Inspection and Sampling," DOE EM Fact Sheet, Gunite and Associated Tanks Operable Unit at Waste Area Grouping 1 at Oak Ridge National Laboratory, The Department of Energy Environmental Program, Winter 1995.

2. D. D. Falter, S. M. Babcock, B. L. Burks, P. D. Lloyd, J. D. Randolph, and J. E. Rutenber, "Remote Systems for Waste Retrieval from the Oak Ridge National Laboratory Gunite Tanks," Proc. of the ANS 1995 Winter Meeting, Oct. 29-Nov. 2, 1995, San Franciso, California.

3. H. Jones, B. Rubinger, P. Apperly, G. Battiston, Y. Fillion, and B. Fuller, "Development and Integration of the Light Duty Utility Arm System," Proc. of the ANS 1996 Winter Meeting, Feb. 25-29, 1996, Tucson, Arizona. 
M98003179

|||||||||||||||||||||||||||||||||||||||||||.|| Report Number (14) ORNL/CP--95937

subl. Date (11) 199702

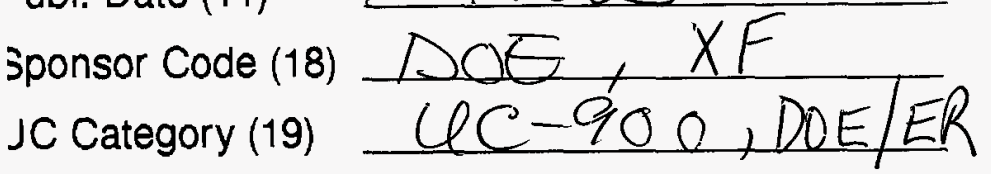

DOE 